\title{
Enhancing Pre-Service Teacher Training: The Construction and Application of a Model for Developing Teacher Reflective Practice Online
}

\author{
Mark Brooke \\ Department of Linguistics and Modern Languages, Hong Kong Institute of Education, Hong Kong, China \\ Email: mbrooke@ied.edu.hk
}

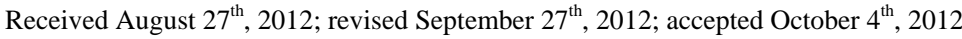

\begin{abstract}
Reflective practice is an essential component of pre-service teacher training programs. It facilitates the linking of theory and practice and empowers trainees to seek reasons behind their practices and their beliefs. These help novices to evolve as they witness their own teaching philosophies emerging. This research took place over 18 months and comprised 3 case studies of eight weeks with 3rd year ESOL trainees on their first intensive block practice in Hong Kong state schools. The research suggests that an online environment is an effective one in supporting and developing reflective practice during these periods. This was facilitated by asking trainees to apply an online model to scaffold reflections. These reflections were then posted and discussed by all case study members. They were also explored further using online moderator asynchronous Socratic dialogue to prompt further reflection. Findings demonstrate that a deep level of reflection is attainable in this context, albeit relatively rare, using the online medium.
\end{abstract}

Keywords: Pre-Service Teacher Training; Reflective Practice; Asynchronous Computer-Mediated Communication (ACMC); Action Research

\section{Introduction}

Reflective practice for pre-service teachers is an essential component of any preparation program (Grossman, 2008; Ostorga, 2006). Reflection is particularly important today with the emphasis on student outcomes (Ward \& McCotter, 2004) which consider it as a performance competency for teachers (Council for Exceptional Children, 2009) and an accreditation standard for teacher education programs (National Council for Accreditation of Teacher Education, 2008). In Hong Kong's education system, university-led teacher education programmes are driven by reflective teaching. In fact, in the last 20 years, this model has been at the heart of its initial teacher education programmes across the SAR.

\section{The Purpose and Aim of the Study}

The Hong Kong Institute of Education is the largest teacher education provider in Hong Kong. 84\% of Hong Kong's primary school teachers and 30\% of HK's secondary school teachers are graduates of the HK Institute of Education. The purpose of the study was to analyse the nature of reflective practice in this researcher's context. In other words, the themes most commonly examined by trainees during their practicum. Following on from this purpose, the aim was to develop a process exploiting the online environment to guide trainees to develop their reflective practice. Thus, the following research question emerged: how can the reflective practice of pre-service teacher trainees be developed through the online environment?

\section{Rationale for the Study}

Some take a practical standpoint and argue that, due to the fact that the end-of-practicum portfolio reflection is nearly always an individual task, it is better to leave students to reflect in peace and quietude through their learning journals. In addition, due to their lack of experience, student teachers during field experience practicum are much more inclined to focus on the pragmatic and immediate problems in the classroom, such as trying out instructional approaches and dealing with classroom management issues. For them, attempting to develop reflective thinking skills to encompass consideration of political, moral and ethical issues is beyond the scope of their first intensive training. Others take a much more critical view and argue that all teachers (whether pre-service or in-service) should be encouraged from the outset to share their reflections and, in true constructivist style aid each other towards higher realms of reflection. These experts also argue that new and old teachers are increasingly constrained by institutional forces, including school district policies on curriculum, instruction and professional development (Lieberman \& Miller, 1991); text-book companies, class sizes decisions, and tight exam-oriented syllabi selected by governing bodies. With all of this top-down, centralized policy-making, a need to reflect on political, moral and ethical issues is quintessential to understanding one's position vis a vis one's school, one's district and one's society.

\section{Literature Review}

\section{Defining Reflective Practice}

According to Zeichner and Liston (1996), there are many features that define reflective practice in teacher training. Quintessential to this model is a cycle of planning, provisioning, acting, data collecting, assessing, reflecting and planning again 
for a subsequent step. However, there are also other elements that help to define it. The reflective process is more often than not, considered as an individual process. However, should it be more social and if so, how can this be facilitated? Regarding the content of reflection: should it strive to include critical analyses incorporating more general, political, moral and ethical issues (as defined by Sparkes-Langer et al., 1990)? Finally, concerning the time frame exemplified in Schon's "reflection in action" and "reflection on action": is it possible to facilitate both reflections that take place relatively quickly in relation to the event and reflections that require much thought over a longer time frame?

\subsection{Reasons Why the Online Environment Can Impact on Reflective Thinking}

The online environment has been growing rapidly in importance in the last decade as a tool to develop reflective practice in teacher education (Davis \& Roblyer, 2005, Galanouli \& Collins, 2002). It is believed that with a high volume of online interaction in a virtual learning environment such as Blackboard or Moodle, focused topic-related discussions raise participants' levels of critical reflection (Galanouli \& Collins, 2002; Murillo, 2008; Simonsen, Luebeck, \& Bice, 2009; Yang, 2009). Reasons for this are that all postings are available to trainees at all times due to the open access nature of the environment. This gives recourse to discussions throughout the eight-week practicum. In addition, because of the asynchronous nature of the environment, communication is not subject to the stresses of online planning as is face to face interaction. This offers its users time to produce a more considered discourse (Garrison, 2009). The fact these considered reflections are shared with peers renders this medium preferable in teacher education to traditional book journaling.

Despite these notions, Salazar et al. (2010) report that more research is required in the use of online forums for fostering reflective practice among pre-service teachers of English language learners (ELL). Although the number of online discussions among pre-service teachers increased as their community Project TEACH evolved, the complexity in thinking about educational issues did not. What is needed in the research is a systematic exploration of how teacher educators can stimulate reflective practice online. It is hoped that findings from this study will be of use to teacher educators who are working online with their trainees by providing empirical evidence of the impact of frameworks developed to facilitate higher level, critical reflection.

\section{Methods and Approaches}

\section{Action Research}

The action research framework provided an essential structure to direct the research, in particular, the model cycle offered by Nunan (1993) was applied: it moves from the awareness of a problem; to an investigation about the problem; to a formulation of possible solutions; an intervention implementing possible solutions; then an observed outcome and the reporting of that outcome. To move from one of the stages to the next in this cycle, a great deal of reflection, action and evaluation of action is normally required.

Prior to the first case study, a very basic plan for the action research had been prepared to "develop participant reflection”. This was to ask learners to apply a well-known set of learning cycles (Argyris \& Schon, 1978, see Figure 3) to their classroom experiences. However, feedback from participants communicated the need for scaffolding; the model was found to be too abstract. It was thus decided that scaffolding of the double loop learning process might facilitate its use. After three case studies of trial and error action research and relevant academic research while the case studies were being conducted, this became the "Model for developing teacher reflective practice online” (see Figure 1).

\section{Participants}

Each case study consisted of six third-year, pre-service male and female teacher trainees. These students are part of a fouryear BEd programme in English Language teaching for both primary and secondary state schools in Hong Kong. The students aged between 20 and 25 years of age and were from Hong Kong and various regions of the People's Republic of China. Despite their training in teacher education, participants, prior to this research, had received little, if any, training in developing reflective practice.

\section{Conceptual Framework of the Research}

The tools used to develop reflection are presented in diagrammatic form in Figure $\mathbf{1}$ below. They are then described more fully in Figure 2.

\section{Reflective Tools}

To engage trainees in systematic questioning and reflecting, a process to be followed online consisting of 3 phases was set up. The first phase involved guiding trainees to implement two reflective frameworks. Framework 1 is adapted slightly from

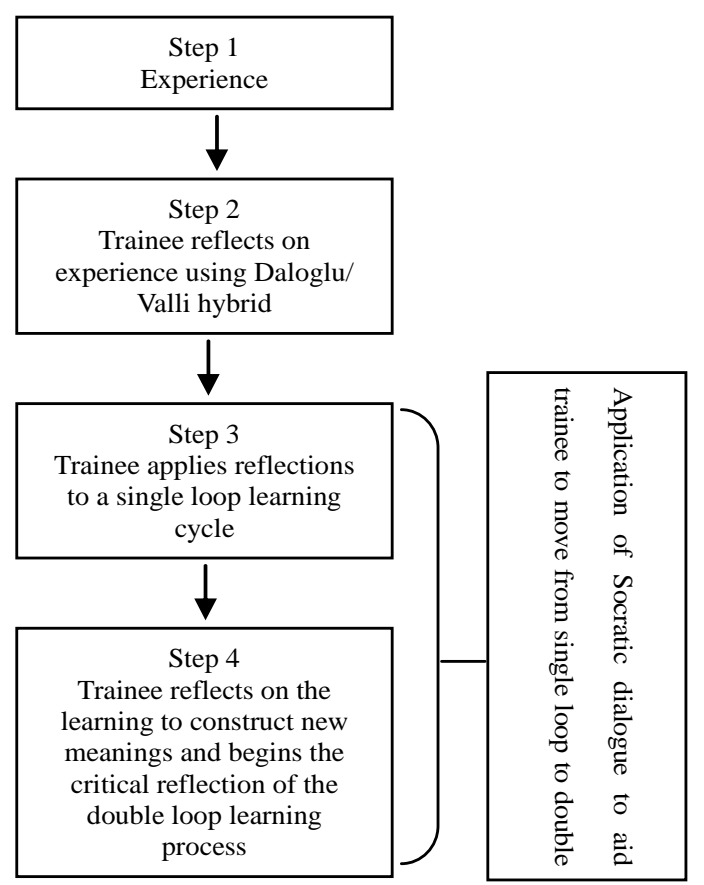

Figure 1.

Model for developing teacher reflective practice online. 
Daloglu (2002). Framework 2 is from Valli (1993). The second phase involved the learning cycle from Argyris and Schön, (1978) known as the single loop learning cycle. The third phase involved the learning cycle from Argyris and Schön (1978), known as the double loop learning cycle. In order to guide trainees through this process, tutor Socratic dialogue (Bakhtin, 1990) was used by embedding questions and comments into students' texts to encourage critical reflections.

\section{Daloglu’s (2002) Questioning Framework}

Trainees were asked to answer the 4 questions put forward by Daloglu:

- What I already knew but benefited from observing/teaching in school;

- What I did not know but learnt from my observations/ teaching in school;

- What I would like to implement in my own teaching;

- My comments on and reactions to the experiences I have had.

This framework was specifically constructed for pre-service trainees following a practicum placement period in local state schools in Turkey. Daloglu reports that this framework was very successful as guidance in paper journal writing. What made this researcher choose it as part of the conceptual framework was its explicit focus on observations, not only classroom teaching. For Daloglu, trainees should be involved in peer observation systems. They should also have the opportunity to observe more experienced, supporting teachers during block practice. These experiences can also have a great deal of impact in building a teacher's skills.

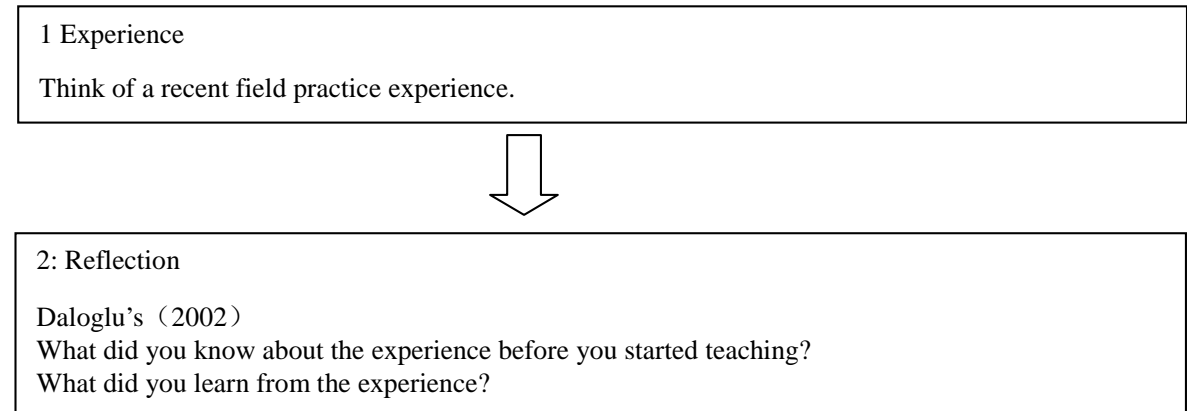

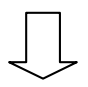

3: Generalization

Please use Valli's (1993) notion of deliberative reflection to base your experience in theory.

Are there any books, lectures, classroom observations or advice from peers/ tutors you can use to help you understand the experience? How does it help you to do this?

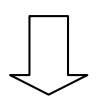

\section{4: Testing}

Applying Daloglu's (2002) third point: what would you like to implement in your own teaching to deal with the experience? Trial your idea (s)

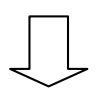

5: Post-testing 1

My comments on and reactions to the intervention that I have just carried out. Have you made any discoveries? Did you implement any new practice (s)? Reflect on the success /outcome of this intervention. Do you plan to make any further changes in the near future?

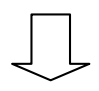

6: Post-testing 2

Look back on the cycle from steps1 to 5 and consider the following question. What are your comments and reactions to the experience I have had? Are there any paradigm shifts or new understandings emerging? In other words, do you interpret the situation differently now? If yes, please explain.

Figure 2.

Template to facilitate double loop learning. 

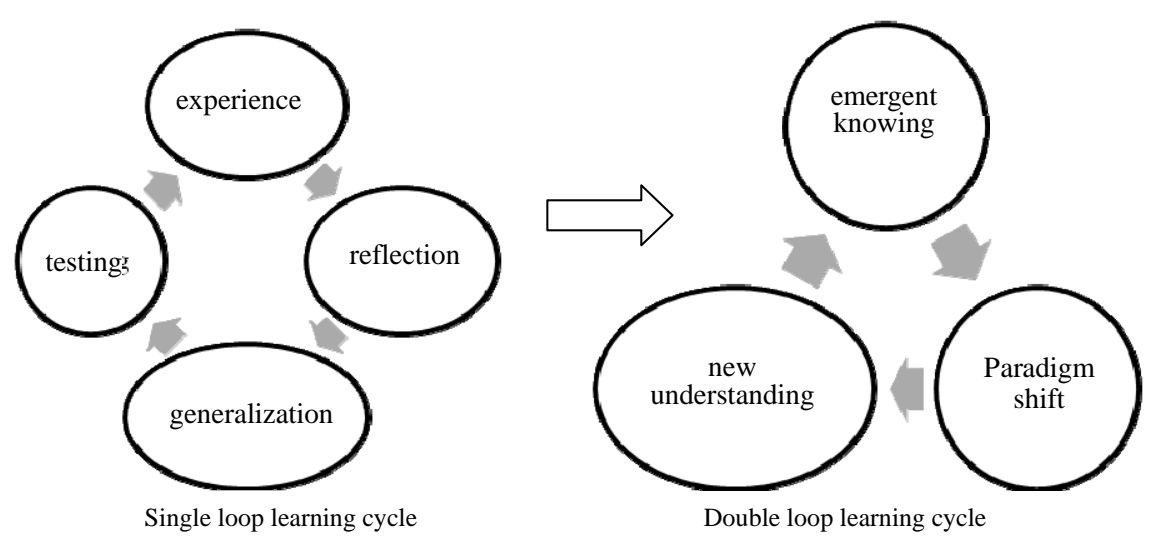

Figure 3.

Argyris \& Schon's single and double loop learning cycles.

\section{Valli's (1993) Notion of Deliberative Reflection}

Where many teacher educators focus most attention on experiential learning, Valli gives equal weight to dialectical reflection (personal, experiential reflective content) and deliberative reflection (reference to the academic literature in the field). The importance of reading and sharing literature about teaching written by other valued practitioners and researchers is thus very present in her typology. Valli (ibid) thus asks pre-service teachers to embrace theoretical content. Pre-service teachers should be encouraged to search out relevant literature.

\section{Argyris and Schon's (1978) Single and Double Loop \\ Learning Cycles (See Figure 3)}

The stages of learning of the single loop followed by the double loop learning cycles are revealed below:

For the single loop learning cycle, a practitioner:

- becomes aware of a puzzle at the experience stage;

- then conducts a process that attempts to "make sense" and "make meaning" at the reflection stage;

- then works with the meanings emerging and uses these meanings to create understandings about the puzzle at the "generalization" stage;

- then tries out interventions in practice to deal with the puzzle investigated at the "testing" stage.

The "making sense" and "making meaning" stages require the participant to know what and why something happened. The "working with meaning" is more complex and might involve the consideration of past experiences and the predictions of future actions. There could therefore be a restructuring of meaning. However, with this model, reflection involves an improvement of the status quo and therefore, is not designed to build critical reflection by discussing the broader issues in the educational system. This is provided by the double loop learning cycle which contains "emergent knowing" and "paradigm shift". This has been designed specifically for a re-evaluation of the status quo and a process of deep learning. As Moon (1999: p. 123) argues, it is the "most advanced stage named on the map of learning".

By following a double loop learning process, trainees are guided to confront basic assumptions behind ideas or policies and to seek the modification of their underlying beliefs and conceptions as well as those of the institutions in which they serve. This process of critically questioning the status quo occurs at the "emergent knowing" stage of the double loop learn- ing cycle. It then leads to a "paradigm shift". The reflections based on this shift it is hoped, will help to build new understandings about teaching and learning.

\section{Socratic Dialogue}

Socratic dialogue is an open-ended kind of dialogue. It is Bakhtin (1990) who contrasted it with Magistral dialogue. It may commence similarly to Magistral writing but after the first reading, the text becomes a mutually-constructed body of writing personalized for and shaped by the reader by the interjecttions made. Thus, according to Gustafson, Hodgson \& Tickner (2004), unlike Magistral dialogue, the aim of Socratic dialogue is not to reach a predetermined end, as is often the case with Magistral dialogue. When involved in Socratic dialogue, the interlocutors are not distanced from each other. They are involved in creating conditions for intimacy, and experiencing difference as something productive and essential. It is therefore the creation of a very different connection between reader and writer than the one who knows and the one who needs to know as is the case with Magistral dialogue, which presupposes this hegemonic relationship.

\section{Design}

\section{Data Collection}

This researcher collated the data every week using the collect thread tool on the Blackboard discussion forums. Once the collect tool is selected, the postings are displayed. A user needs to select the tick box of individual learners or simply tick the first box for all postings to be selected. These can then be collected in various ways: chronologically, in descending or ascending order (descending lists the postings from the latest first; ascending lists the postings from the earliest first); from the author's first or last name; from the subject of the posting; or by collecting them on the dates on which they were uploaded. For this research, threads were collected on a chronological basis in ascending order every week. They were then coded and sorted.

The total number of postings collected was 397. All posts were first analysed and sorted into categories based on the content of their reflections. The postings were then further analysed for their level of critical reflection based on Sparks-Langer et al.'s (1990) hierarchal framework for reflective pedagogical thinking. 


\section{Content Analysis}

\section{Data Grouping 1: Content of Reflection}

The content of participant reflections was analysed through multiple observations over the 3 case studies. This framework can be seen to be a hybrid integrating Shulman's (1987) and Ho and Richards' (1993) categories along with a construct from this researcher "asking questions about teaching and requests for advice from peers and the trainer". These are presented below:

- Life/Logistics (personal life situations or logistics of field experience and/ or teacher education program) from Shulman;

- Content Knowledge (subject matter knowledge related to the body of knowledge in TESOL such as linguistics and phonology) from Shulman;

- Discussing broader issues in education (adapted from Shulman);

- Discussing instructional approaches, teaching theories, methods and strategies used from Ho and Richards;

- Demonstrating self awareness from Ho and Richards;

- Asking questions about teaching and requests for advice from peers and the trainer (constructed by this author).

\section{Data Grouping 2: Levels of Reflection}

Sparks-Langer et al.'s (1990) hierarchal framework for reflective pedagogical thinking was applied to measure the level of participant reflection. The 7 levels are provided below and are supported by examples from this researcher's data:

- $\quad$ No descriptive language;

- A simple, layperson description: for example, "I asked students to do group work";

- Events labeled with appropriate pedagogical terms or concepts: "I asked students to do collaborative group work";

- Explanations with traditional or personal preferences given as the rationale: "A friend of mine recommended a classroom management practice called 'power teaching'. It is really useful I think.”

- Explanation of an event using pedagogical principle(s): "According to the schedule, Tina and I should teach the reader Spiderman until 4th May. In our methodology course, we learnt that readers are a good tool because the language is contextualized."

- Explanation with principle/theory and consideration of contextual factors such as student characteristics or community factors: "I enjoy teaching English with readers because the language is always contextualised. But it is rather difficult because my students are not used to doing reading activities in class. I am now striving to work out some activities in order to increase students' incentive to read and learn from Spiderman.”

- Explanation with consideration of ethical, moral or political issues: "I asked students to do group work. However, I divided them according to their seats. This is not the most appropriate way for grouping. I will observe students' performance and make some changes according to their learning abilities. I think this is very important for dealing with diversity in class. I want my students to learn to work cooperatively together in class, to help and value each other.”

\section{Research Procedures}

As the research was a spiral of experiential learning through action research cycles, the following description of the proce- dures for the study is presented in chronological order as a recount. The description reveals how the final "Model for developing teacher reflective practice" was constructed, which can be found as Figure 1 and as an expanded version in Figure 2.

\section{Step 1}

The first step in the process was to train students to ask themselves questions about their experiences and reflect on these. This was then followed by training students to make a "generalization" about these reflections. Scaffolding for the initial reflection on experience task of the single loop learning cycle was given by asking students to apply Daloglu's (2002) questioning framework to their experiences. In addition, trainees were asked to apply Valli's (1993) notion of deliberative reflection to these answers in order to facilitate the transition from "reflection" to "generalization". In order to reflect deliberatively, trainees must refer to writings from experts in the educational field and through the literature, seek knowledge from these experts to help them understand the problem and make them feel that their own experiences are perhaps more common than they think.

\section{Step 2}

The next step was to progress from step 1 to a simple action research cycle to train students to consider ways of improving their practice based on the reflections and generalizations that they had made. To do this, trainees were asked to consider how they might apply the Daloglu (2002)/Valli (1993) combination to an action research process through the single loop mechanism presented by Argyris and Schön (1978); in other words, to move from "generalization" to "testing". However, feedback from trainees suggested that the Daloglu (2002) framework alone was inadequate for this transition. In order for the Daloglu framework to fit in entirely with the Argyris and Schön cycle, there was an adjustment made to it. This was an added statement: "my comments on and reactions to the intervention that I have just carried out". In addition, it soon became clear that the cycle graphic did not facilitate all of this questioning and that another graphic design would be more applicable. The single loop learning cycle was transformed into a flowchart (the single loop learning process goes as far as post testing 1) instead to make the visual aid more effective.

\section{Step 3}

The next stage in the process was the facilitation of the move from the single to the double loop learning cycle. This meant trainees were to engage in more critical reflections to include much broader issues. Using Sparks-Langer et al.’s (1990) hierarchal framework for reflective pedagogical thinking, this is the highest level, level 7, "explanation with consideration of ethical, moral or political issues". To do this, another scaffolding procedure was used. The notions from the double loop were added to the flowchart (post testing 2) to guide trainees through the conceptual reflections on paradigm shift and new understanding.

\section{Step 4}

It was still found that some participants found the shift from the single loop to the double loop learning cycle problematic. Thus, throughout steps 3 and 4, Socratic dialogue was embed- 
ded in online postings to prompt reflection by asking questions and making comments on trainee writings. Sometimes these comments would guide trainees to rewrite or expand their reflections; sometimes they would contradict reflections and invite trainees to consider other possible solutions to problems or different ways of seeing events; sometimes they would guide trainees to refer to appropriate literature in the field or to return to prior postings written by them or other participants about a particular topic, which might add to the online discussions.

\section{Findings}

\section{Quantitative Data Presentation}

It can be observed that the majority of the postings (32\%/125) were concerned with Life/Logistics (personal life situations or logistics of field experience and/or training program). The next most-common theme was "Demonstrating self awareness" (25\%/ $100)$. The third most-common theme was "Discussing instructional approaches, teaching methods and strategies used" (22\%/ 88 ). The next three themes only made up $21 \%$ of the total. These were "Asking questions about teaching and requests for advice from peers and the trainer" (7\%/28), "Content Knowledge" $(4 \% / 16)$ and "discussing broader issues in education" $(10 \% / 40)$.

\section{Qualitative Data Presentation}

\section{The Application of the Model Constructed}

The following is a successful double loop learning reflection by a trainee emerging from the "model for developing teacher reflective practice online". This posting is an example of the $10 \%$ or 40 examples gathered of the topic "Discussing broader issues in education", which can be considered as the desired outcome of the double loop learning process.

At first, in the single loop section, the trainee's reflections focus on classroom management details such as correct macroplanning and timing of lessons as well as the importance of setting up routines. Therefore, these reflections focus entirely on classroom matters. With the double loop learning cycle reflections, the belief system can be seen to have undergone a change, moving from wanting to create a more controlled teaching and classroom regime to wanting a more creative one by making learning more engaging. It is evident that this is the beginning of an "emergent knowing", which could lead to a whole shift in paradigm. Finishing the lesson on time is no longer the focus of attention. The trainee's understanding of the problem has evolved as he realizes that it was not the real issue. The real issue was the amount of teacher talking time and consequently, the lack of student talking time. The emerging understanding is one that seeks to facilitate student communication and collaboration in the L2 and foster good citizens through the development of focused discussions on important life issues. This is quite a move away from the original issue of timing. It demonstrates the potential for empowerment of the double loop learning cycle. Using Sparks-Langer et al.'s (1990) framework, examples of level 6 "explanation with principle/theory and consideration of contextual factors such as student characteristics, subject matter, or community factors" and level 7 "explanation with consideration of ethical, moral or political issues" are both present. Student characteristics are part of the reflection as the trainee discusses that they tend to enjoy more opportunity for communication in class. Ethical and
Daloglu \& Valli combination: "I had learnt from my studies that there is a strong linkage between the curriculum, syllabus, module, unit and each lesson. If stages are well-linked, students are led to a deeper and deeper understanding of the topic. According to Doff (2000: p. 98), 'stages' refer to the 'main focus of the activity'."

Testing: "From teaching, I have learnt that even in one lesson, a set routine for my class could benefit my teaching and save time during the lesson. Setting classroom procedures can help the smooth running of instructional activities and reduce 'the frequency which teachers need to give instructions for daily classroom events' (Hue \& Li, 2008). Most of my lessons now start with a quiz on the topic from the previous session or a checking of homework. Students are able to use the time before I come to class to revise the topic."

Generalization: "A good lesson should be timed appropriately as I understand students do not like to spend the whole recess with the teacher still teaching. With the help of good lesson planning and good use of classroom management skills, a lesson should be able to end on time."

Post testing: "Students of mine gave me comments on my teaching at the end of this week. They told me that I did a great job in finishing the lesson on time. I think that through good planning, the time for teacher talk can be minimized and allow students to express their ideas more and to practise what they have learnt. This should encourage all the students to talk more in English. And I think my students enjoyed this very much as they even asked me to allow them to stay after school to practise the interview questions we wrote."

Paradigm shift: "This is a more student-centered approach to teaching. I think that too much time is used by the teacher in class. In my school, students use Cantonese not English to learn their other subjects. They are not forced to use English in school. So, it is important to give students time to practice and learn to communicate in English with each other."

New understanding: "In traditional classrooms, teachers take up over 80\% of the talking time (Walsh, 2006). They are concerned with exams and covering the content of the syllabus. But I believe our role is to develop students' communication and collaboration skills through group discussions. These discussions should be about important issues to help students form opinions. This helps to make the child a good citizen. So I think that if teacher talking time is well-managed, it can be reduced to allow students' more practice time.'

political issues are present as part of the reflection as the trainee discusses his role of forming good citizens who can express their opinions about important subjects. Thus, through the double loop learning cycle, the trainee has gone beyond theories of social learning and scaffolding to how the classroom can adopt more communitarian values. One might say that there is the root of democracy in the trainee's posting.

\section{The Application of Socratic Dialogue}

Socratic dialogue was found to be a skilful practice in an asynchronous environment. The following moves in this order were found to be most effective:

1) Phase 1

Through embedding comments, teacher educators should first demonstrate that they have a clear understanding of the trainee's problem by empathizing and then restating the problem in their own words. This builds trust and confidence in the teacher educator's guidance is fostered.

2) Phase 2

The teacher educator embeds questions which encourage reflection and guide trainees to explore other ways of seeing a problem. This is done to enable trainees to entertain new ways of seeing. 
Below is an example of phases 1 and 2:

Jade: "I planned to teach grammar (expressing time, place and manner) and letter writing in the first week. But after the first lesson in which I only finished 1/5 of my lesson plan, I realized that students couldn't learn too much in one lesson."

Trainer: "I always did that too when I started out teaching -in fact, I still over-plan!!! Can you keep what you've planned for the next lesson?”

3) Phase 3

The third phase is to move reflections on. To do this, certain moves were found more effective than others: these were the "probe", "inform” (both fact and opinion) and ask/clarify moves. In addition, moves such as "eliciting other trainees" facts/opinions' and asking for consensus on topics were found to be effective in constructing participant interaction and building collaborative learning. The data below reveals how these were embedded over a period of 5 days.

\section{Discussion}

In this section, the quantitative data will first be examined. Then, new learning evident in the qualitative data from the model applied will be discussed; in particular, how the application of this model online, rather than through traditional paper journaling is effective. Following on from that, the problems encountered and the solutions applied when using the Argyris and Schon double loop learning cycle will be discussed.

\section{Analysis of Quantitative Data}

Similarly to Simonsen, Luebeck \& Bicean's (2009) findings, this research demonstrates that trainees are overwhelmingly concerned with the practical problems that they face during their first intensive practicum experience such as timetabling and classroom practice. This is probably because of their inexperience in the field, which leaves them little time to focus on broader issues involved in their practices. That said, "self awareness" constituted a large percentage of the topics discussed. This category is a part of the single loop learning cycle and it demonstrates that there was an effective application of the cycle offered by Argyris and Schön (1978), in particular, "My comments on and reactions to the intervention that I have just carried out”. Thus, participants were actively involved in action research cycles.

\section{Analysis of Qualitative Data}

\section{New Learning Applying the Online Model}

Feedback from learners at the end of each case study made it very clear that because they were able to read and re-read postings and discussions applying the online model for developing reflection spread out from the beginning to the end of the block practice period, new learning was effectively facilitated. This is because participants used this data to aid them in the final reflective practice assignments that they were required to write. In other words, trainees were able to analyze how their knowledge and understandings had been built progressively during the eight weeks of each case study. Participants who scored highly on Sparks-Langer et al.'s (1990) framework noted that this opportunity for retrospection was significant for the development of critical reflection. This is significant because

\section{Day 1:}

Jade: "I planned to teach grammar (expressing time, place and manner) and letter writing in the first week. But after the first lesson in which I only finished 1/5 of my lesson plan, I realized that students couldn't learn too much in one lesson.”

Trainer: "I always did that too when I started out teaching - in fact, I still over-plan!!! Can you keep what you've planned for the next lesson? It's good that you decided not to do the final activity (encourage): that is something that a lot of teachers do not do. They really want to finish their plan no matter what (inform/fact). Did you feel disappointed? (Probe) What did you find was the reason for not finishing your plan? (Probe) Could there have been too much material to get through? It is common to over-estimate students' abilities? It's also common to spend too long on an activity. (Probe)"

Jade: “All of these! And I didn't plan for taking the register at the beginning or playing a game. The students said their teacher plays games with them if they work hard so we played a game near the end of the class.”

Trainer: "The register can often be time-consuming. Sometimes you can do it quietly and quickly when the students are involved in a task during the lesson. (Inform/fact). Do the students want to play games every lesson? (Ask/clarify)"

Jade: "I think it is a bit difficult to play games every lesson. I will try to make games a part of the lessons but maybe not every lesson."

Trainer: "How about other people? Have you found the same? Is there any advice any of you can offer?” (Eliciting other trainees' facts or opinions')

\section{Day 2:}

Jasmine: "I also have too high expectations for students. A teacher from the UK told me to never take anything, including what students know for granted."

Jenny: "I agree-it's very difficult judging how much to teach during a lesson-especially before you know your class.”

Day 3:

Jade: "I have revisited my scheme of work and I taught 3/5 of my plan in my 2nd lesson. I am improving in my time management which I think is very important. I lost my sense of time during lessons.”

Day 4:

Trainer: “That's great to hear. Time goes so fast when you have to deal with so much at once. (Inform/opinion) What do you think about the heavy syllabus you are asked to teach? (Probe) How many of you would like more time to try out innovative practices and experiment with things you learned during your course?” (Asking for consensus on topics)

Day 5:

Jenny: "I have had to teach a lot of worksheets on grammar. I would like my classes to be much more flexible so I could experiment more."

the online program is not merely concerned with the final product of learning, which is often the sole concern of the traditional, paper journaling method. It is more process-oriented, learning-centered pedagogy. This relates to social constructivist pedagogy (Bruner, 1961; Glasersfeld, 1989; Vygotsky, 1978; Wertsch, 1997) and is a major characteristic of recent trends in the use of technology for educational purposes. In addition, feedback from participants on the asynchronous nature of the online environment made it clear that it was possible for these trainees as English language users to concentrate more on the grammar of their messages as well as the content of their reflections during online discussions than they would if these interactions were face to face. It was made clear that this too 
had helped trainees to construct more critical analyses of their experiences and relate these to their peers. They were also more able to offer more considered replies in discussions to their peers. Thus, the quality of the content of the interaction was greater than it would have been through normal face to face interaction.

\section{Problems Participants Experienced Working with the Double Loop Learning Cycle}

The first difficulty participants encountered stems from transforming the dialectical content of experiential learning theory to a more abstract form of understanding through the process of generalization. Kolb (1984) refers to this process as “abstract reconceptualization”. In order to generalize, trainees need to move into the realm of theory and to seek out new information from external sources which will help them to develop ideas about their experiences.

Through this research, it has been made evident that one method to guide trainees through the process of "abstract reconceptualization", and scaffold the "generalization" phase of the cycle is to make explicit the fact that trainees should link their experiences with expert opinion from the relevant teacher training literature in the field. One effective way of doing this is by highlighting Valli's notions of "dialectical" and "deliberative" reflection. By raising awareness of this distinction, trainees were better equipped to understand that expert practitioners rely on both at all times to help them. It is this researcher's opinion that deliberative reflection empowers the trainees because it substantiates their intuitive knowing by making evident that their understandings are shared and have a history. In addition, it increases knowledge by offering discussions on the same problems that trainees are facing and discusses further strategies already proven to deal with these. In the example trainee posting above, the notion of "stages" has been applied to deliberative reflection. The trainee cites an expert who describes "stages" as the "main focus of the activity". For a trainee who must learn how to write lesson plans for important observations, this kind of knowledge is quintessential. What terms do I use in the lesson plan to describe the procedure of teaching and learning? Should I use "events”, “activities”, "parts”, "sections” or "stages"? Through recourse to deliberation, the trainee's question has been answered.

The second difficulty encountered is the lack of scaffolding for the transfer between the single and double loop learning cycle. Within the single loop learning cycle, trainees are required to ask: "this is what happened" -> "this is what might work to deal with it" -> "was my intervention effective?" However, the 'working with meaning' is more complex because in order for trainees to transfer to the double loop learning cycle, a second further removed past tense is required. Participants need to ask themselves what they have learned from the experience. This requires a stepping back from the experience and rediscovering the learning event as vividly as possible so that a re-evaluation of that experience can take place. This is then followed by linking this "emergent knowing" to a "new paradigm" or new belief system constructed based on reflection on action. This "new paradigm" should seek to understand the ex- perience by considering much broader issues than those found in the classroom such as community factors and ethical, moral or political issues. It is evident that this is a complex process of reflection. To scaffold the procedure, a stepping stone was provided bridging the single and double loop learn- ing cycles. On the template (see Figure 2), there is a post-testing 1 and a post-testing 2 phase. This was designed to enable trainees to function within these 2 past time frames. The post-testing 2 reflection can then be connected to the "emergent knowing", which then, through skilful application of Socratic dialogue, can further be extended to facilitate new understandings. For this research, the use of Socratic dialogue to guide trainees to deeper learning was found to be essential.

\section{Benefits of Applying Socratic Dialogue}

Phases 1 and 2 are demonstrated clearly in the example dialogue between this researcher and a trainee. The teacher educator's response is minimal but it reveals how understanding and empathy were provided at the outset. By applying the term "over-plan", the trainer sums up the trainee's posting to demonstrate understanding of the main message. The trainer then provides empathy by stating that he too makes the same mistake as do many others. This helps to generalize the problem. The "encourage and enable" phase was effectuated by working with meaning and guiding the trainee to understand that perhaps now it was possible to further micro-plan what has already been prepared. In other words, work out how to make the rest of what has been planned extend over more lessons.

It can be observed from the second set of data on Socratic dialogue that it is feasible to conduct asynchronous discourse with several trainees at once over several days. As already noted, phase 3 consists of various moves. These can be used to guide trainees to think beyond the classroom to understand their experiences in light of new potential understandings. This is the crux of the double loop learning cycle. In this example, the trainer guides trainees to notice that they have very busy schedules given to them by their schools where they are being placed. They are therefore experiencing time management issues. This of course brings into question what the practicum is for. Is it for training pre-service teachers to copy older in-service teachers (learning what might be called knowledge of practice and the maintenance of the status quo), or is it to provide trainees with an environment in which they can apply the conceptual and practical knowledge that they have learned during their studies at their institute or university of education and develop their own understandings of their contexts and their own teacher identities? In this case, the constraints that they are subjected to prevent innovation, action research, and fundamental change in teaching practice from the bottom-up.

\section{Limitations of the Study}

\section{Content Analysis}

As with any action research project supplying qualitative data, there are limitations. This research was of a relatively small size: only 3 8-week case studies were conducted. Had the research taken place over a much longer time frame, the tools used for content analysis would be more valid because there would be more samples to use for standardization. In addition, for data grouping the thematic analyses conducted could be critiqued for subjectivity. To deal with this issue, sample postings of the coding categories were subjected to inter-rater reliability. Another rater was asked to categorize ten random samples for coding stage 1 (topic of reflection) and ten random samples for coding stage 2 (level of critical reflection) and inter-rater reliability was high for both. The rater agreed with nine decisions out of ten made for stage 1 and all 10 decisions 
made for stage 2 .

\section{Conclusion}

The application of the model for 'developing teacher reflective practice online' has been created to facilitate genuine, critical reflection which fosters personal empowerment leading to self transformation and potential societal change from the bottom-up. The online environment with its particular characteristics aided the effectiveness of this model. This was because learners were able to focus on the learning process as much as the product required. They were also able to share and build ideas and opinions together and to communicate asynchronously. This enabled them to reflect more than they might while enacting face to face interaction. Further research might focus on the process of systematically deconstructing this model developed to report how this was done and the kind of challenges faced by trainees during the removal of these scaffolds.

\section{REFERENCES}

Argyris, C., \& Schön, D. (1978). Organizational learning: A theory of action perspective. Reading, Mass: Addison Wesley.

Bakhtin, M. M. (1990). Art and answerability. Austin, TX: University of Texas.

Brantley-Dias, L. D. M., Frisch, J., \& Rushton, G. (2008). The role of digital video and critical incident analysis in learning to teach science. American Educational Research Association Annual Meeting, New York, URL (last checked May 2012). http://msit.gsu.edu/IT/Dias/AERA_08_Dias.pdf

Daloglu, A. (2001). Fostering reflective teaching from the start: Journal keeping in pre-service teacher education. In J. Burton, \& M. Carroll (Eds.), Journal writing. case studies in TESOL practice series (pp. 87-101). Alexandria, VA: Teachers of English to Speakers of Other Languages, Inc.

Davis, N. E., \& Roblyer, M. D. (2005). Preparing teachers for the "schools that technology built": Evaluation of a program to train teachers for virtual schooling. Journal of Research on Technology in Education, 37, 399-409.

Doff, A. (2000). Teach English: A training course for teachers (14th ed.). Cambridge: Cambridge University Press.

Galanouli, D., \& Collins, J. (2002). Using unmediated computer conferencing to promote reflective practice and confidence-building in initial teacher education. Journal of Information Technology for Teacher Education, 9, 237-254. doi:10.1080/14759390000200084

Garrison, D. R. (2003). Cognitive presence for effective asynchronous online learning: The role of reflective inquiry, self-direction and metacognition. In J. Bourne, \& J. C. Moore (Eds.), Elements of quality online education: Practice and direction. Needham, MA: The Sloan Consortium.

Grossman, P. (2008). Responding to our critics: From crisis to opportunity in research on teacher education. Journal of Teacher Education, 59, 10-23. doi:10.1177/0022487107310748

Gustafson, J., Hodgson, V., \& Tickner, S. (2004). Identity construction and dialogue genres-How notions of dialogue may influence social presence in networked learning environments. In Proceedings of the fourth international conference on networked learning (A researchbased conference on e-learning in higher education and lifelong learning). Lancaster.

Ho, B., \& Richards, J. C. (1993). Reflective thinking through teacher journal writing: Myths and realities. Prospect, 8, 7-24.

Hue, M. T., \& Li, W. S. (2008). Classroom management: Creating a positive learning environment. Hong Kong: Hong Kong University Press.

Kagan, D., \& Tippings, D. (1991). How teachers' classroom cases express their pedagogical beliefs. Journal of Teacher Education, 42, 281-291. doi:10.1177/002248719104200406

Kolb, D. A. (1984). Experiential learning: Experience as the source of learning and development. Englewood Cliffs, NJ: Prentice-Hall.

Lieberman, A., \& Miller, L. (1991). Revisiting the social realities of teaching. In A. Lieberman \& L. Miller (Eds.), Staff development for education in the 90s (pp. 72-82). New York: Teachers College Press.

Murillo, E. (2008). Searching usenet for virtual communities of practice: Using mixed methods to identify the constructs of Wenger's theory. Information Research, 13, 386. URL (last checked July 2009). http://informationr.net/ir/134/paper386.html

Moon, J. (1999). Reflection in learning and professional development. London: Kogan Page.

Ostorga, A. N. (2006). Developing teachers who are reflective practitioners: A complicated process. Issues in Teacher Education, 15, 520.

Salazar, Z. A.-M., \& Fox, N.-L. (2010). On-line professional learning communities: Increasing teacher learning and productivity in isolated rural communities. Journal of Systemics, Cybernetics and Informatics, 8 .

Schön, D. (1988). Coaching reflective teaching. In P. Grimmett, \& G. Erickson (Eds.), Reflection in teacher education (pp. 19-29). New York: Teachers College Press.

Schön, D. (1991). The reflective turn: Case studies in and on educational practice. New York: Teachers College Press.

Shulman, L. S. (1987). Knowledge and teaching: Foundations of the new reform. Harvard Educational Review, 57, 1-22.

Simonsen, L., Luebeck, J., \& Bice, L. (2009). The effectiveness of online paired mentoring for beginning science and mathematics teachers. The Journal of Distance Education, 23, 51-68.

Sparks-Langer, G. M., Simmons, J., Pasch, M., Colton, A., \& Starko, A. (1990). Reflective pedagogical thinking: How can we promote it and measure it? Journal of Teacher Education, 41, 23-32. doi:10.1177/002248719004100504

Stringer, E. T. (1996). Action research: A handbook for practitioners. Thousand Oaks, CA: Sage.

Toh, W. S. (2001). Measuring practicum student teachers' reflectivity: The reflective pedagogical thinking scale. URL (last checked 17 December 2012). http://www.ipbl.edu.my/BM/penyelidikan/2001/2001_toh.pdf

Valli, L. R. (1993). Reflective teacher education programs: An analysis of case studies. In J. Calderhead, \& P. Gates (Eds.), Conceptualizing reflection in teacher development (pp. 11-22). London: The Falmer Press.

Walsh, K. (2006). Teacher education: Coming up empty. Arresting Insights in Education, 3, 1-6.

Ward, J., \& McCotter, S. (2004). Reflections a visible outcome for preservice teachers. Teaching and Teacher Education, 20, 243-257. doi:10.1016/j.tate.2004.02.004

Yang, S. H. (2009). Using blogs to enhance critical reflection and community of practice. Educational Technology \& Society, 12, 1121.

Zeichner, K. M., \& Liston, D. P. (1996). Reflective teaching: An introduction. Mahwah, NJ: Erlbaum. 